December 2013

\title{
Connecting Aga Khan University's nine campus libraries across three continents through a shared library system
}

Ashraf Sharif

Aga Khan University, ashraf.sharif@aku.edu

Normand Demers

Aga Khan University, normand.demers@aku.edu

Follow this and additional works at: http://ecommons.aku.edu/libraries

Part of the Library and Information Science Commons

\section{Recommended Citation}

Sharif, A., Demers, N. (2013). Connecting Aga Khan University's nine campus libraries across three continents through a shared library system. IFLA Journal, 39(4), 319-326.

Available at: http://ecommons.aku.edu/libraries/7 


\title{
Connecting Aga University's Nine Campus Libraries Across Three Continents Through a Shared Library System
}

\author{
Ashraf Sharif \\ Aga Khan University \\ Normand Demers \\ Aga Khan University
}

Corresponding Author:

Ashraf Sharif, Systems Librarian, Aga Khan University Libraries, Karachi, Pakistan.

Tel: 922134864451

Email: ashraf.sharif@aku.edu

\section{Author Biographies:}

Ashraf Sharif is Systems Librarian at Aga Khan University. He acquires MA in Library Science from University of the Punjab, Lahore, Pakistan. He also holds a Master's degree in Mass Communication from the same institution. He joined Aga Khan University, Karachi, Pakistan in May 2009. Prior to this, he worked with Lahore University of Management Sciences (LUMS), Lahore, Pakistan as Senior Librarian, System \& Services. He has been on the panel of instructors of Pakistan Library Association's Computer Training Center, Lahore, from 1998-2003, where he taught library automation to working librarians and students of library schools. Overall he has 13 years' experience of academic institutions, including 10 years as Systems Librarian in the institutions of higher education in Pakistan. He was team lead for implementation of ILS in 9 AKU libraries across three continents.

Email: ashraf.sharif@aku.edu; ashraf.sharif@gmail.com

Normand Demers is University Librarian at Aga Khan University. He holds a Master's degree in Library \& Information Studies from McGill University, Montreal, Canada; Postgraduate Diploma in International Management from the National School of Public Administration, Université du Québec, Montreal, Canada. Normand has over 27 years' experience of setting up and managing libraries and information units in academic and research contexts in several developing countries, as well as in Europe and in North America. He also worked for the Organization for Economic Cooperation and Development (OECD) in Paris and the International Livestock Research Institute (ILRI), a member of the UN-based Consultative Group on International Agricultural Research (CGIAR), in Ethiopia and Kenya.

Email: normand.dermers@aku.edu 


\begin{abstract}
The Aga Khan University (AKU) is the only university in the developing world that is serving through its eleven campuses spread across eight countries and three continents. It has a network of nine libraries, although small in size, in four developing courtiers in two regions (South Asia and East Africa). The university has recently implemented a library management system to integrate all nine libraries in four counties using a single shared database. The purpose of this paper is to share our experience of implementing the industry standard-base state-of-the-art library system. The geographical location of AKU libraries and multilingual collections makes this experience more significant. Keeping in view the complexity of geographical locations, multilingual collections, different time zones, and diversity of staff involved, one can consider it a unique occurrence in the field of library and information science.
\end{abstract}

\title{
Keywords
}

Library and information science; Integrated library systems; Library management systems; Symphony; Pakistan; East Africa; Developing countries 


\section{Introduction}

Aga Khan University (AKU) received its charter from the Government of Pakistan in 1983. It is a private and autonomous university that promotes human welfare through research, teaching and community service. Based on the principles of quality, access, impact and relevance, the University has campuses and programs in Afghanistan, East Africa, Egypt, Pakistan, Syria and the United Kingdom. Its facilities include teaching hospitals, nursing schools and medical colleges, the Institutes for Educational Development, the Examination Board and the Institute for the Study of Muslim Civilizations. Faculties of Arts and Sciences are in Karachi, Pakistan and in Arusha, Tanzania are in the planning phase.

AKU is perhaps the only university in the developing world that is providing education, health and social services through its eleven campuses spread across eight countries and three continents. It has a network of nine libraries, although small in size, in five countries of South Asia, East Africa, and the UK. The university has recently implemented a library management system to integrate all libraries using a single shared database.

The purpose of this study is to share Aga Khan University Libraries' experience in integrated library automation (ILS), project from the feasibility study to data conversion and system migration, including system selection, system and client configuration, functional testing and problem reporting, training and lessons learned. Following a one-year selection effort, Symphony was chosen as the new system for AKU libraries. This study also discusses the challenges faced by the project team in system migration.

After successful implementation of the system, nine AKU libraries are sharing their resources from different geographical locations in Pakistan, Kenya, Tanzania, Uganda and the UK. There is a single search interface to see library holdings of each or all AKU libraries, which is very helpful for resource sharing and interlibrary loan. Users of AKU are very happy to see a new user-friendly interface. They are enjoying the empowerment to renew and hold their books remotely through web-based secured login. Also they are able to receive alerts for overdue and new arrivals in their respective fields. With the implementation of this new system, the internal processing activities of libraries are improved and library staff across all libraries are following the same processes and helping each other. They are also learning the new standards supported by this system, including RFID, Unicode, EDI, and several others. 


\section{Aga Khan University Library Network}

One the recommendation of a consultant, Dr. Ernie Ingles, who was hired a consultant to AKU in 2004, the Office of the University Librarian was established in 2008 (Ingles, 2005). This office is responsible for the overall management and development of Libraries and Learning Resources throughout the University's international campuses. The objective of the Office of the University Librarian is to facilitate the creation of a network of AKU Libraries which, while maintaining their individuality, can share resources and services with all libraries in the network.

Aga Khan University Libraries provide strong support to students, faculty and researchers for their study, teaching and research through its network of nine libraries. Table-1 lists the AKU libraries:

Table 1: AKU Libraries

\begin{tabular}{cll}
\hline SN & Name & Location \\
\hline 1 & Faculty of Health Science (FHS) & Karachi, Pakistan \\
2 & Institute for Educational Development (IED) & Karachi, Pakistan \\
3 & IED Professional Development Centre (IED-PDCN) & Gilgit, Pakistan \\
4 & IED Professional Development Centre (IED-PDCC) & Chitral, Pakistan \\
5 & Faculty of Health Science (FHS) & Nairobi, Kenya \\
6 & Faculty of Health Science (FHS) & Dar es Salaam, Tanzania \\
7 & Institute for Educational Development (IED) & Dar es Salaam, Tanzania \\
8 & Faculty of Health Science (FHS) & Kampala, Uganda \\
9 & Institute for the Study of Muslim Civilization (ISMC) & London, UK \\
\hline
\end{tabular}

The library collections include books, current journals, back files of print journals, educational reports, audiovisual aids, theses and dissertations and digital media. AKU libraries also provide access to online journals, books and other electronic resources. The total print collection comes to 135,000 titles including archives of print journals. AKU libraries have access to 12,000 e-journals and 60,000 e-books from 30 subscribed databases.

\section{Library automation project}

The Aga Khan University Libraries wanted to replace their legacy systems with the state-of-the-art integrated library system in order to enhance library services as well as to facilitate internal processing activities. They were looking for an ILS that offers more flexibility and functionalities than the older systems. The AKU libraries were using a variety of standalone systems, including some using in- 
house developed software built on Informix and FoxBASE. Table 2 shows the various software used by AKU libraries.

Table 2: Systems previously used in AKU Libraries

\begin{tabular}{|c|l|l|l|}
\hline Sr. & Name of AKU Library & Type of system & System in use \\
\hline 1 & Faculty of Health Science (FHS), Karachi-Pakistan & In-house developed & Informix-based \\
\hline 2 & Institute for Educational Development (IED), Karachi-Pakistan & In-house developed & Informix-based \\
\hline 3 & IED Professional Development Centre, Gilgit, Pakistan & In-house developed & $\begin{array}{l}\text { FoxBASE- } \\
\text { based }\end{array}$ \\
\hline 4 & IED Professional Development Centre, Chitral, Pakistan & In-house developed & $\begin{array}{l}\text { FoxBASE- } \\
\text { based }\end{array}$ \\
\hline 5 & Faculty of Health Science (FHS), Nairobi-Kenya & Off-the-shelf & Libsoft \\
\hline 6 & Faculty of Health Science (FHS), Dar es Salaam-Tanzania & Off-the-shelf & Libsoft \\
\hline 7 & $\begin{array}{l}\text { Institute for Educational Development (IED), Dar es Salaam- } \\
\text { Tanzania }\end{array}$ & Off-the-shelf & Libsoft \\
\hline 8 & Faculty of Health Science (FHS), Kampala-Uganda & Off-the-shelf & Libsoft \\
\hline 9 & Institute for the Study of Muslim Civilization, London-UK & Off-the-shelf & Liberty2 \\
\hline
\end{tabular}

Also libraries were cataloging their materials according to their own understanding; without following any cataloging standards. For example Libraries in East Africa were using some local format, not a MARC compliant. There was no comprehensive integrated online public access catalog (OPAC) of AKU libraries.

In 2009, the university decided to acquire an ILS and to migrate all AKU libraries to this new system. A project charter was written and got approved from the concerned authorities for the whole process, from planning to selection to implementation and go-live (AKU, ILS Steering Committee, 2009).

\section{Project Objectives}

The following were major objectives of the project:

- Integrate libraries into a network using a shard library system

- Provide user access to library resources of all satellite libraries in the network,

- Follow standard practices in library operations, and services. This requires preparing policies procedures to be followed uniformly by the users

- Ensure compliance with international library standards

- Empower the users to be able to interact with the system through secure login

- Use add-on systems. such as RFID system, ERMS, discovery platforms, and other

The Project was divided into two phases:

- Project planning

- Project implementation 
Since one of the AKU library (ISMC library, London) was using an older version of Symphony, it was agreed that this library will not be part of the implementation project until it is upgraded to the latest version of Symphony. Only after that their data will be allowed to be imported into the central catalog for searching.

\section{Project Planning}

This phase was started in September 2009 and was completed in December 2010. In this phase, initial planning and background work was carried out. A comprehensive 32-page Request For Proposal (RFP) was prepared and sent to the following ILS vendors (AKU, ILS Working Committee, 2009):

1. Ex Libris for ALEPH

2. Innovative Interfaces Inc. for Millennium

3. SirsiDynix for Symphony

4. VTLS for Virtua

A project charter was written and got approved from the concerned authorities to supervise the project. A list of major stakeholders, project technical and functional scope, project deliverables, dependencies, deadliness, critical success factors, potential issues and risks, and acceptance criteria were defined in the project charter. Project committees and teams were constituted and project manager was appointed for smooth running of the project, from planning to selection to implementation and go-live of the project.

"One of the most important decisions for the library manager is the selection of a library management system" (Calvert, 2006). Keeping in mind this experience, the ILS Working Committee selected Symphony, a product of SirsiDynix as ILS for AKU libraries, as this system was closely matching with the needs of AKU libraries. Price of this system was also within the AKU budgetary provisions. After negotiation with the sales representatives of SirsiDynix, and vetting from AKU legal department, the project was granted to Arabic Advanced Systems (AAS) in December 2010. AKU nominated its systems librarian as project manager, whereas AAS appointed its technical manager as project manager.

The selection of the system was carried out after a careful evaluation of responses to RFP from the vendors. The reason to drop other systems varied. One vendor didn't respond to RFP. One declined stating that they didn't have any representation to meet the administrative requirements, whereas another vendor was not meeting AKU system and budgetary requirements. 


\section{Project Implementation}

Once the licensing agreement was signed with the vendor, a project implementation plan (AKU ILS Implementation Plan, 2010) was agreed and singed off between project managers of AKU and AAS. An online kick-off meeting was held in first week of January 2011 and the project implementation was formally started.

\section{Training site preparation}

According to the project plan, the AKU technical team had to prepare a site and hand it over to the vendor for remote installation of the system. Required hardware was setup and configured by AKU technical team within one week. Microsoft Windows was installed as a system platform and Microsoft SQL was installed as a database. The IT infrastructure implementation used state-of-the-art failover clustering and virtualization technologies. A two-node failover database cluster was formed and application server was installed in a virtual environment with failover support. The virtual environment was created inside this cluster for efficient utilization of IT resources. A secure remote session was created for vendor interactions and application website was published for access over Internet. The hardware was commissioned at central data centre of AKU principal campus in Karachi, Pakistan. After this setup, the servers were handed over to the vendor for remote installation of Symphony. Libraries always prefer to migrate to the latest version/release of the system (Khurshid, 2010), so vendor was asked to install the latest version of Symphony which was then version 3.4.0.

\section{Remote installation of the system}

Once hardware was handed over to the vendor, they started remote installation on the servers and got the job done within the timeline of 30 days. That was included installation and configuration of Symphony database, Symphony application and customization, and Symphony e-library installation and customization. AAS provided Symphony client to AKU project manager for installation on client machines at AKU libraries. Also a sample set of data was provided by the vendor for testing purposes. AKU installed the client in the all AKU libraries in Pakistan and East Africa and tested the sample data and found the functions of the system satisfactory.

\section{Data conversion and migration}

One of the most critical tasks was providing the AKU data to the vendor for uploading into the new system. The required format for metadata was MARC21. But since no AKU library was using full MARC format, this could become the major bottleneck. A timely strategy was designed to handle this problem in the project initiation phase. According to this strategy, AKU libraries were requested to download full MARC data of existing records from libraries around the world using Z39.50 gateways of the . Library of Congress, National Library of Medicine, University of Alberta, Harvard University, Oxford University, and some regional libraries were bench-marked for record 
downloading through copycat. MarcEdit, a free software, developed by Terry Reese, was used for this purpose. This tool searches and extracts MARC data from selected libraries using Z39.50 protocol. This is really a wonderful tool, but it doesn't search multiple libraries simultaneously. To overcome this limitation, another tool Copycat was used. Initially the trial version of this tool was used for evaluation, and later this tool was purchased from a US based company Surpass.

Under this strategy for AKU Pakistan libraries, around 31\% MARC records were downloaded from different libraries around the world before the implementation started. This was an effective strategy and no problem was encountered at the stage of implementation. Rest of the $69 \%$ records were mapped to MARC tags so that each book in the library would be searchable with major access points. Table-3 shows the bibliographic data for AKU-Pakistan libraries. It was decided that this mapped data will be cleaned and converted into full MARC data within two years.

Table 3: AKU libraries-Pakistan - data migrated

\begin{tabular}{|l|r|r|r|r|}
\hline \multicolumn{1}{|c|}{ AKU - Pakistan } & \multicolumn{1}{c|}{$\begin{array}{c}\text { Total } \\
\text { Collection }\end{array}$} & \multicolumn{1}{c|}{$\begin{array}{c}\text { Copycatted } \\
\text { data }\end{array}$} & Mapped data & $\begin{array}{c}\text { \%age copycat } \\
\text { MARC records }\end{array}$ \\
\hline FHS, Karachi & 22,000 & 9,595 & 12,405 & 43.61 \\
\hline IED, Karachi & 24,291 & 8,534 & 15,757 & 35.13 \\
\hline PDCN, Gilgit & 15,690 & 6,312 & 9,378 & 40.23 \\
\hline PDCC, Chitral & 8,372 & 425 & 7,947 & 5.08 \\
\hline TOTAL AKU-Pakistan & $\mathbf{7 0 , 3 5 3}$ & $\mathbf{2 4 , 8 6 6}$ & $\mathbf{4 5 , 4 8 7}$ & $\mathbf{3 1 . 0 1}$ \\
\hline
\end{tabular}

For AKU East Africa libraries, since they have been using small library software Libsoft, all 17,798 records were extracted in MARC tags and imported in the new system. So no copycat strategy was adopted for this data.

This data was handed over to the vendor in MARC files (*.mrc). The vendor tested this data and found perfect for uploading into the system. The data uploading was completed with one month's targeted timeline. AKU libraries tested this uploaded data for one week and found it satisfactory. So an acceptance message was sent to the vendor as a sign-off. After data uploading, the system was operational and ready to use.

\section{Onsite training of library staff}

As agreed in project implementation plan, the vendor was responsible to provide on-site training to AKU library staff. This was divided into two phases. In first phase, the vendor had to send the trainer to Karachi to give training to AKU Pakistan staff. For this purpose, a training site was prepared at Faculty of Health Sciences Library (FHSL) Karachi, Pakistan and library staff from other AKUPakistani libraries was invited to FHSL Karachi. Two library staff from IED-PDCN Gilgit, a small city in northern part of Pakistan on Karakorum Highway, at some 1500 kilometre from Karachi and 
some 8000 feet above sea level, reached Karachi. Another library staff member from IED-PDCC Chitral, a small town at 8500 feet above sea level travelled to Karachi to attend this training session. This was a 5-days intensive training of purchased modules of the system. After this training in Karachi, AKU libraries Pakistan started a pilot run in the presence of the trainer. Being a part of agreement, the vendor had to send the trainer to Karachi for training plus 5-days post-training fine tuning of the system. So during this pilot run, the trainer (who was also a key person for implementation from vendor side) did the necessary post-data uploading fine tuning of the newly installed system.

In the second phase of training, the vendor sent a trainer to FHS Nairobi, Kenya to provide training to AKU-East Africa library staff. So library heads from FHS Dar es Salaam, Tanzania, IED Dar es Salaam, Tanzania, and from FHS Kampala, Uganda were invited to come to Nairobi for this training. This was another 5-days intensive training for AKU-East Africa library staff.

Once the onsite training and test run was over for both Pakistan and East Africa, the project acceptance was granted to the vendor for completion of successful project within the given timelines.

\section{Go-live and post go live scenario}

In the project charter, the go-live date was estimated to May 30, 2011. All the project deliverables were accomplished till April 15, 2011. So the project was complete before its deadline. But this time margin was used to further critical testing of the system to avoid and foresee any unseen problem. However no critical problem was encountered during this period. The libraries (both from Pakistan and East Africa) found the system quite stable and showed their satisfaction. So in third week of May, all library heads gave a signoff and system went live on May 30, 2011. The Online Public Access Catalog of AKU was launched on the same day naming it as SAFARI (Search Access Find And Retrieve Information). This is single platform for all AKU libraries and accessible at http://safari.aku.edu.

As a precautionary measure, a 7 day time was fixed for post go-live monitoring. The technical staff was held standby and alerted for any unseen situation. This test run was successful and no discrepancies were seen in this testing phase and project was signed off.

\section{Major Challenges and Mitigations}

At the stage of planning and initiation, some potential issues and challenges were identified. After discussions with technical and functional teams, a mitigation strategy formulated to address these issues. 


\section{Geographical diversification}

This was a big issue that was discussed while planning for this project, as AKU libraries are spread over five countries in three continents, and in three different time zones. Since ISMC library London was technically out of this project scope, so there were no more questions about this. The difference between Pakistan and East Africa was still there. The recommended mitigation for this issue was that the system will be implemented in two phases. At the time of implementation, it was felt that since the database for Pakistan and East Africa libraries was the same, we could avoid dividing the various tasks into phases. So taking all stakeholders on board, it was decided that the system will be implemented simultaneously in both regions.

Since all libraries would be sharing one database, and hardware would be commissioned in main campus at Karachi, Pakistan, what if the server went down or the internet outrage between two regions was interrupted for longer time. In this case libraries in Pakistan would not suffer, but libraries in East Africa would badly suffer. The circulation module would not work until the transactions were performed. Also the OPAC would not be available to end-user. The vendor told that the system provides a facility for offline transactions, so this utility will cover the short time service outage between the two regions. After discussions with technical teams and with AKU-IT department, it was decided to have a backup server at AKU-Nairobi campus to avoid taking any risksk. So the matter was discussed with the vendor and there was an agreement to have a read-only backup server in Nairobi. That server would not be a live server, but serve as a passive backup server. The cataloging data would be exported to this server through a script so that the end-users of East Africa would be able to use OPAC.

\section{Change management}

One of the most significant aspects of the ILS implementation has been the change in the library's policies, procedures and services (Feng, 1983). Keeping in view this potential bottleneck, a strategy was designed and it was made sure that all library staff was mentally prepared to adapt themselves to this change. So they were involved in every policy and procedure change. This strategy worked very well and all library staff participated in changing policies and procedures and they felt ownership and responsibility and became part of this change process happily.

\section{Multilingual materials}

Since AKU is operating in different countries, the libraries also have materials in languages other than English. In AKU Pakistan libraries, a significant number of items were in Urdu and some local languages. Table 4 provides detail of non-English material. 


\begin{tabular}{|l|r|r|r|}
\hline \multicolumn{1}{|c|}{ Table 4: Multi-lingual material } \\
\multicolumn{1}{|c|}{ AKU - Pakistan } & \multicolumn{1}{c|}{ Urdu } & \multicolumn{1}{c|}{ Other } & \multicolumn{1}{c|}{ Total } \\
\hline FHS, Karachi & 210 & 31 & 241 \\
\hline IED, Karachi & 2,741 & 235 & 2,976 \\
\hline PDCN, Gilgit & 1,950 & 65 & 1,970 \\
\hline PDCC, Chitral & 750 & 36 & 750 \\
\hline \multicolumn{1}{|c|}{ TOTAL } & $\mathbf{5 , 6 5 1}$ & $\mathbf{3 6 7}$ & $\mathbf{6 , 0 1 8}$ \\
\hline
\end{tabular}

To catalog non-English books, AKU libraries planned to provide training of cataloging in dual script (English and local languages) to its staff. Library of Congress (LOC) office Islamabad was contacted and requested to provide training to AKU staff for this purpose. The LOC office accepted our request and we sent four librarians for this training. Now staff is doing Romanization according to the ALALC Romanization Tables, and making dual scripts entries in the catalog. Below screenshot (FIG 1) is showing OPAC display of dual script entries:

\section{FIG 1}

\section{Dual-Script OPAC Display}

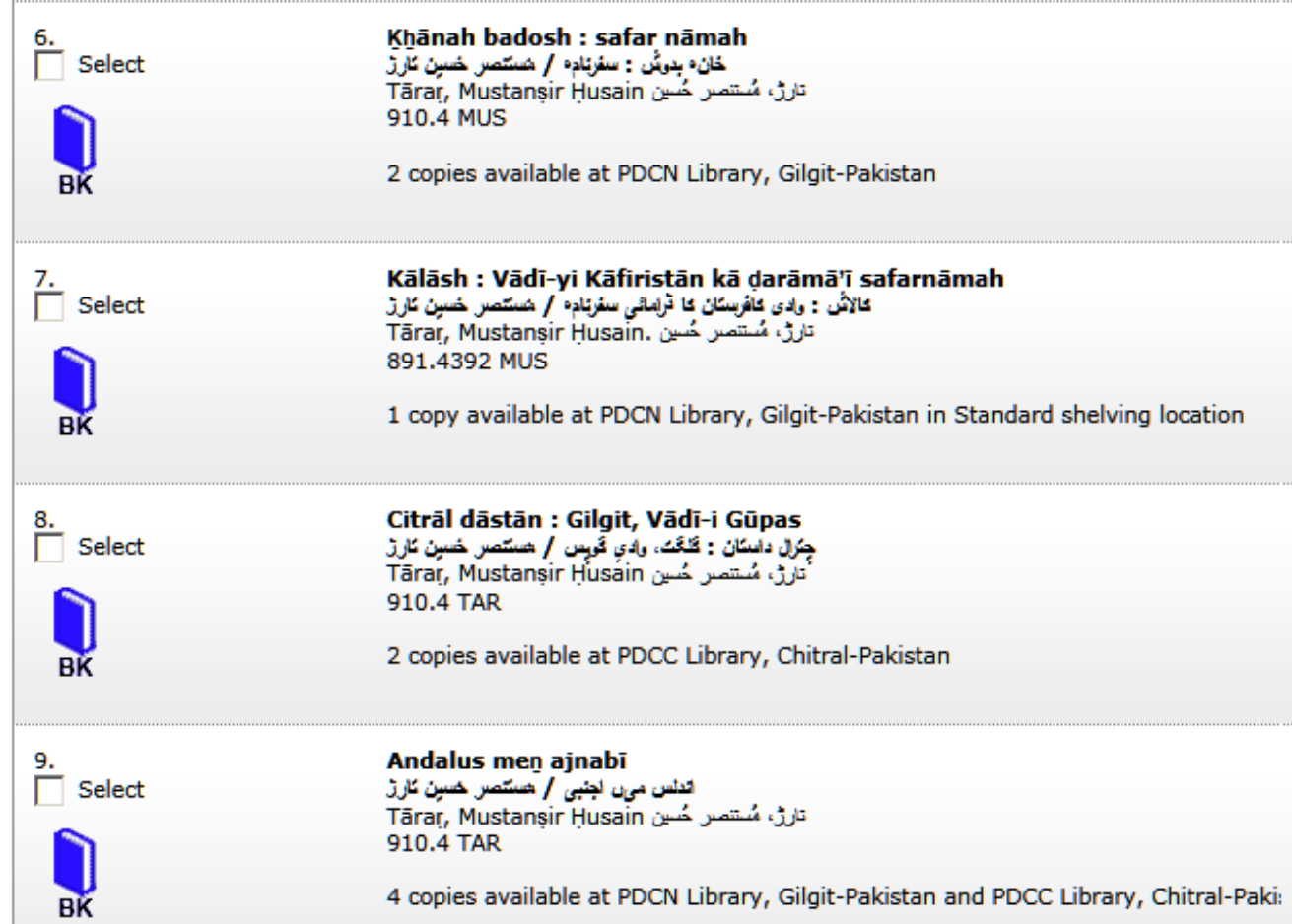
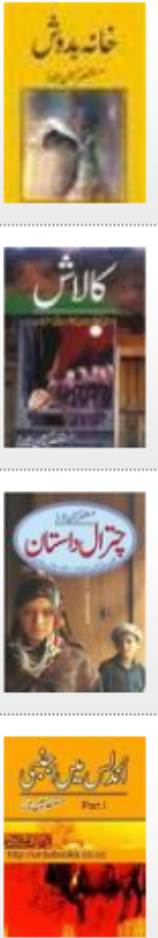


\section{Lesson Learned}

Although this project was started after a careful review of available resources, the following lessons were learned from the various phases of project implementation:

- Required hardware should be available on hand before the signing the licensing agreement with the vendor. This helps to avoid any delays in timelines.

- Contract agreement (between the institution and the vendor) should be submitted to Legal Office for vetting well in time due to certain technicalities involved.

- Finance department should be taken on board, as payment plan including tax issues are part of the agreement. All this should be part of the planning phase.

- Institutions should avoid $100 \%$ advance payment to the vendor. Breakup of total payment into four equal instalments on some agreed deliverables has been a good experience.

- Taking all libraries on board well before time and keep them involve in every step of the project has been a great success. This works well as change management tool.

- Proper documentation of each and every step is very important to keep track of all activities involved.

\section{Conclusion}

Aga Khan University is perhaps the first university in the developing world that is serving eight countries and has a network of eight libraries in four developing courtiers in two regions (South Asia and East Africa). It was really a difficult task to integrate these libraries using single shared database keeping in view the geographical locations and multilingual collections.

The project implementation was started in the first week of January and the system went live on 30th May, 2011. Symphony was chosen after a comprehensive review of major international library systems. Symphony is a product of SirsiDynix (http://www.sirsidynix.com), one of the world leaders in library automation industry, and has presence in thousands of libraries all over the world. The implementation vendor for this project was Arabian Advanced System (AAS), Beirut office.

The AKU libraries online catalog called SAFARI (Search Access Find And Retrieve Information), is accessible at http://safari.aku.edu. The new system provides access to the holdings of all AKU libraries with a single search term. Symphony is an open system and operable with any system using any platform.

A lot of hard work went on to get the project implemented within the given timelines. The project accomplished successfully and on time due to the team work of both professional librarians and nonlibrarians. 


\section{References/Additional Readings}

Aga Khan University. http://www.aku.edu

Aga Khan University, ILS Steering Committee (2010) Integrated library system migration: Project charter. Karachi.

Aga Khan University, ILS Working Committee (2009) Request for proposal for integrated library system. Karachi.

Aga Khan University Libraries’ Catalog. http://safari.aku.edu

ALA-LC Romanization Tables. http://www.loc.gov/catdir/cpso/roman.html

Audrone G (2004) Project Management: Tools and techniques for today's ILS professional. Journal of Documentation 60(6): 694-697.

Cyril CHF, Gary F and Patricia CK (1983) Implementation of the Integrated Library System:

University of Maryland Health Sciences Library. Bulletin of Medical Library Association 71(3): 312-316.

Ernie I (2005). Aga Khan University: Review of library services. (Unpublished Report) Karachi: Aga Khan University.

Frank C (2007) ILS migration in the 21st century: some new things to think about this time around. Computers in Libraries 27(7): 60-62.

Jason V (2004) Library's integrated online library system: Assessment and new hardware implementation. Information Technology and Libraries 23(2): 50-57.

MarcEdit. http://people.oregonstate.edu/ reeset/marcedit/html/downloads.html

Philip C and Marion R (2006) RFPs: a necessary evil or indispensable tool? The Electronic Library 24(5): 649-661.

Shelley N and Ed R (2004) Standards: Perspectives of an integrated library systems vendor. Serials Review 30(1): 10-14.

Suzanne J, Donna H and Brian T (2003) A case study of ILS migration: Aleph500 at the University of Iowa. Library Hi Tech 21(1): 44-55.

William CD (2009) Integrated library systems: Where are they going? Where are we going? Journal of Academic Librarianship 35(5): 482-485.

Zahiruddin K and Saleh AA (2010) System migration from Horizon to Symphony at King Fahd University of Petroleum and Minerals. IFLA Journal 36(3): 251-258.

Zhonghong W (2009) Integrated library system (ILS) challenges and opportunities: A survey of U.S. academic libraries with migration projects. The Journal of Academic Librarianship 35(3): 207220. 